\title{
PerCursos
}

\section{O conceito de Pré-história nos livros didáticos de História no}

\section{Brasil}

\section{Resumo}

Este artigo trata sobre o conceito de Pré-história nos livros didáticos de História no Brasil. A intenção é demonstrar o diálogo existente entre a historiografia acadêmica e a literatura didática acerca da periodização histórica que organiza a narrativa presente no livro didático, sobretudo, após a criação e consolidação do Programa Nacional do Livro DidáticoPNLD, responsável pela avaliação da qualidade historiográfica e pedagógica dos livros didáticos a partir da década de 1990. Para tal, analisamos os cinco livros didáticos de História do $6^{\circ}$ ano mais usados nas escolas públicas brasileiras (PNLD 2017-2019), utilizando os pressupostos metodológicos estabelecidos pela Análise de Conteúdo (BARDIN, 2010) e a História dos Conceitos (KOSELLECK, 2006), na busca de compreender as mudanças e as permanências nos sentidos atribuídos ao termo PréHistória (FUNARI, 2013). Os resultados obtidos com a investigação revelam as estratégias desenvolvidas pelos livros didáticos de história para manter o termo Pré-História na narrativa central do texto didático, mesmo após as reconfigurações dos livros didáticos estimuladas pelo PNLD, na tentativa de superar a perspectiva cronológica e eurocêntrica da historiografia escolar. Nota-se que, as estratégias se materializam na adoção de uma nova semântica (palavra, termo, discurso) para explicar a "origem" da história, da escrita e da sociedade ou no uso de nova acepção para o termo Pré-história.

Palavras-chave: Pré-história. Livros didáticos. Programa Nacional do Livro Didático.

\section{Ana Lúcia do Nascimento Oliveira}

Pós-Doutora em História pela

Faculdade de Letras do Porto.

Doutora em História pela Univ.

Federal de Pernambuco - UFPE.

Professora aposentada da

Universidade Federal Rural e

Pernambuco - UFRPE. Professora do Programa de Pós-Graduação em História da UFRPE.

Brasil

ananascimentoufrpe@gmail.com

\section{Juliana Alves de Andrade}

Doutora em História pela Univ.

Federal de Pernambuco - UFPE.

Professora da Univ. Federal Rural

de Pernambuco - UFRPE e do

Mestrado Profissional em Ensino de

História-ProfHistória da UFPE/UFRPE.

Brasil

julianadeandrade.ufrpe@gmail.com

\author{
Luiz Adriano Lucena Aragão \\ Mestre em História pela Univ. \\ Federal Rural de Pernambuco - \\ UFRPE. Aux. Em Assuntos \\ Educacionais do Instituto Federal \\ de Pernambuco - IFPE. \\ Brasil \\ a.lucena1010@gmail.com
}

\footnotetext{
Para citar este artigo:

OLIVEIRA, Ana Lúcia do Nascimento; ANDRADE, Juliana Alves de; ARAGÃO, Luiz Adriano Lucena. O conceito de Pré-história nos livros didáticos de História no Brasil. PerCursos, Florianópolis, v. 21, n.47, p. 277 - 302, set./dez. 2020.
}

DOI: $10.5965 / 1984724621472020277$

http://dx.doi.org/10.5965/1984724621472020277 


\title{
A teaching practice carried out from the perspective of experimentation and interdisciplinarity through the theme of water and biodiversity in elementary school classrooms
}

\begin{abstract}
This article deals with the concept of Prehistory in history textbooks in Brazil. The intention is to demonstrate the existing dialogue between academic historiography and didactic literature about the historical periodization that organizes the narrative present in the textbook, especially after creating and consolidating the National Textbook Program-PNLD, responsible for the assessment of historiographic quality and pedagogical teaching of textbooks from the 1990s. To this end, we analyzed the five most-used 6thyear history textbooks in Brazilian public schools (PNLD 2017-2019), using the methodological assumptions established by Content Analysis (BARDIN, 2010) and the History of Concepts (KOSELLECK, 2006), in the search to understand the changes and the permanence in the meanings attributed to the Prehistory term (FUNARI, 2013). The results obtained with the investigation reveal the strategies developed by the history textbooks to keep the term Prehistory in the central narrative of the text, even after the reconfigurations of the textbooks stimulated by the PNLD, in an attempt to overcome the chronological and Eurocentric perspective of school historiography. It is noted that the strategies materialize in the adoption of a new semantics (word, term, discourse) to explain the "origin" of history, writing, and society or in the use of a new meaning for the Prehistory term.
\end{abstract}

Keywords: Prehistory. Textbook. National Textbook Program-PNLD. 


\section{Introdução}

O livro [didático] é um artefato impresso em papel, que veicula imagens e textos em formato linear e sequencial, planejado, organizado e produzido especificamente para uso em situações didáticas, envolvendo predominantemente alunos e professores, e que tem a função de transmitir saberes circunscritos a uma disciplina escolar. (FREITAS, 2009, p. 13)

Reconhecer o livro didático como um artefato é, sem dúvida, considerar todos os elementos que compõem sua estrutura: projeto gráfico, textos/narrativas, exercícios etc.; logo, o livro é um artefato que apresenta uma série de signos e significados sobre temas e problemas vivenciados em tempos e espaços pretéritos. O livro didático de História é produzido a partir de alguns critérios (formato linear, sequencial, cronológico) e tem como função servir de instrumento para a difusão do conhecimento histórico no espaço escolar. Em sua forma contemporânea, volta-se para a aprendizagem de estudantes (livro do aluno) e professores (Manual do Professor). Para Circe Bittencourt (2011), Alain Choppin (2004), Flávia Caimi (2013), o artefato (livro) é considerado uma ferramenta didática, um objeto cultural complexo e ícone da tradição escolar, fazendo parte do cotidiano escolar há pelo menos dois séculos.

Por ser um objeto constituído por muitas memórias e histórias, o livro tem sido problematizado e discutido por diferentes grupos de pesquisa. Embora seja bastante pesquisado, nota-se que os estudos se concentram em alguns temas, como, por exemplo, o estudo do conceito de tempo, espaço, classes sociais e história nos livros didáticos de história. Esses elementos figuram como os itens mais pesquisados da lista dos temas estudados na primeira década dos anos 2000. Para Flávia Caimi (2013), os estudos relativos aos livros didáticos podem ser classificados por categorias, conforme apontam os objetos de pesquisas das dissertações e teses, a saber: a) etnias e pluralidade, b) linguagens, c) cidadania, d) usos do livro didático de História pelo professor, e) gênero, f) análise de conteúdo, g) História do ensino de História, h) concepções do livro didático, i) categorias de aprendizagem e j) historiografia. Essa categorização proposta pela autora tem ajudado, sem dúvida, os pesquisadores do campo do Ensino de História a 
acompanhar os estudos desenvolvidos sobre o livro didático e contribuído para ampliação dos debates.

Assim, entendendo as peculiaridades dos objetos de estudo e a necessidade de ampliar ou aprofundar algumas questões, o presente trabalho busca contribuir com os estudos preocupados com os conteúdos a serem ensinados no livro didático, ao observar os usos do conceito de Pré-história nos livros didáticos de história, na tentativa de avançar no debate sobre a periodização histórica e a organização da historiografia escolar. O trabalho buscou compreender como os livros didáticos brasileiros que adotaram a divisão clássica da história "universal” (Pré-História, Idade Antiga, Idade Média, Moderna e Contemporânea) dialogam com as novas perspectivas historiográficas e arqueológicas que refutam as ideias de 'progresso', 'etapas' e 'eurocentrismo'.

Sem dúvida, na tentativa de responder os motivos que levam à permanência desse tipo de periodização (Pré-História e História) na maior parte dos livros didáticos brasileiros, apesar das críticas já formuladas, encontramos algumas estratégias dos livros didáticos que rompem com a ideia de progresso. Logo, a organização da narrativa nos livros didáticos em História e Pré-história não tem apenas uma função didática, mas, política. Então, problematizar a expressão Pré-história é entender o seu lugar no processo de aprendizagem histórica de crianças e adolescentes. Nota-se que, embora, muitos autores continuem usando a expressão, mesmo que criticamente, os livros didáticos atuais reforçam a ideia de que periodizar é fazer seleção dos que entram para a história. Nesse sentido, estudar a presença do termo Pré-história nos livros didáticos contemporâneos é refletir sobre as relações de poder. Marilena Chauí esclarece que “elucidar o sentido da periodização oficial, de sorte a evidenciar que esta não é uma ação teórica desinteressada, mas um Ato de Poder. A periodização produz o lugar da história e, como ele, o da origem legitimada do poder vigente" (CHAUÍ, 1986, p. 7, grifo nosso).

Entender tal ferramenta didática (livro didático) em sua complexidade é também considerar transformações historiográficas vividas no Brasil a partir de 1980. Em relação à política educacional, os anos de 1980 representam uma fase de intensa resistência a um modelo de governo civil-militar (1964-1985) que se fez premente na tentativa de controlar as opiniões e os pensamentos dos cidadãos. Com a supressão de grande parte da 
formação geral e a destruição das humanidades no currículo, sob a pretensão de combater toda e qualquer possibilidade de crítica ao regime autoritário, implantou-se uma lógica de racionalização capitalista com forte controle técnico e burocrático no interior das escolas (ROMANELLI, 1986, p. 61).

A resistência representou, de acordo com Selva Guimarães (2012), a ideia de repensar e criticar os diversos aspectos da Educação, da História e do seu ensino. A História, no período civil-militar, foi posta em uma posição secundária. Um conjunto de situações a desvalorizou: parco financiamento da educação no nível básico e superior, currículos fragmentados, licenciaturas de curta duração e esvaziamento políticopedagógico do debate histórico a partir da presença dos Estudos Sociais.

Diante desse contexto, a partir da década de 1980 há um desdobramento com vista à superação das condições impostas que, segundo a professora Selva Guimarães (2012), foi fruto de lutas e resistências dos profissionais de educação e entre eles, os de História.

Repensamos e criticamos os diversos aspectos constitutivos da educação, da História e seu ensino: a política educacional, os currículos, a gestão, a escola, o ensino e a aprendizagem, os professores, os alunos, os pressupostos, os métodos, as fontes e os temas. Desse movimento, emergiram outras proposições diferenciadas daquelas predominantes, até então, na educação brasileira. (FONSECA, 2012, p. 33)

Esse repensar apontado pela estudiosa se transforma em ações efetivas e na década de 1990, pós-abertura política, e com a democracia se instaurando, o ensino de História passa por uma reformulação com a substituição de Estudos Sociais por História e Geografia, no Ensino Básico. Extinção com base em dispositivos legais das disciplinas Educação Moral e Cívica, Organização Social e Política do Brasil e Estudos de Problemas Brasileiros e a extinção das licenciaturas de curta duração.

\footnotetext{
1 A lei 8.663, de 14/06/1993, revoga o decreto-lei $n^{\circ} 869$ (que vigorava para manter no currículo as disciplinas: OSPB, EPB e Moral e Cívica). A lei substituiu a carga horária destinada às disciplinas do decretolei n 869 para as Ciências Humanas e Sociais (BRASIL, 1993, p. 7885).
} 
A partir de 1994, as preocupações que nortearam as pesquisas acadêmicas adentram o universo da literatura didática com a formulação do documento que estabeleceu a "Definição de Critérios para Avaliação dos Livros Didáticos" MEC/FAE/UNESCO. Esses critérios são publicados, em 1996, através do Guia do Livro Didático, espécie de manual que é indicativo de novos critérios avaliativos bem como de temáticas e recursos didáticos evidenciados na literatura escolar; esses critérios, na área de História, buscam alinhar novos pressupostos teóricos e metodológicos do conhecimento histórico aos livros didáticos de História. Esse alinhamento representa a reescrita do material didático. Essa reescrita, também sinônimo de novas narrativas nos livros didáticos, neste artigo nos interessa para refletir sobre o material didático.

Houve também o aperfeiçoamento da política pública de avaliação dos livros didáticos através do PNLD; inserida a promulgação da nova LDB - Lei de Diretrizes e Bases da Educação - lei 9.493/96; elaboração e implantação dos Parâmetros Curriculares Nacionais (PCNs), que acabou por reformular e atualizar, para a época, as bases curriculares municipais e estaduais no país. Essas transformações impactaram no ensino nas duas décadas subsequentes.

Para compreender-se os resultados produzidos por uma nova historiografia e pelas políticas públicas voltadas para o livro didático no Brasil, apresentaremos uma discussão sobre o lugar do termo Pré-história nos livros didáticos, mostrando como as coleções abordam o tema da periodização clássica; em seguida, analisaremos a pertinência do conceito Pré-história no material didático, e, por fim, como o conceito dialoga com a historiografia acadêmica, na tentativa de redefinir a noção de Pré-história presente nos livros didáticos.

\section{O que falam os livros didáticos de História sobre a Pré-história?}

Estudar o lugar do termo Pré-história nos livros didáticos de História na contemporaneidade requer um esforço intelectual dos pesquisadores do campo do Ensino de História, dado o grande volume de material (livros didáticos) que a historiografia escolar brasileira vem acumulando desde meados do século XIX. Dessa 
forma, busca-se responder ao seguinte questionamento: Os livros didáticos de História do PNLD 2017-2019 trazem o conceito de Pré-história? E criar uma estratégia de trabalho, que permita fazer uma leitura atenta dos textos principais, secundários, boxes, atividades e exercícios. Assim, o conjunto documental que serviu de fonte para as nossas reflexões foram os livros didáticos mais consumidos/distribuídos nas turmas do Ensino Fundamental (Anos Finais) das escolas públicas brasileiras, conforme dados do FNDE de $2017^{2}$. Fizemos esse recorte porque essas coleções representam um número significativo de pessoas com acesso ao conhecimento histórico escolar, dado o volume de livros distribuídos.

Os dados apresentados pelo FNDE revelam que existem, no Brasil, cinco coleções de livros didáticos que são as mais usadas nas aulas de história, conforme demonstra a tabela 1 a seguir:

Tabela 1 - Coleções mais distribuídas do Ensino Fundamental (anos finais)

\begin{tabular}{|c|c|c|c|c|}
\hline Colocação & Nome da coleção & Editora & Autor & $\begin{array}{c}\text { Quantidade de } \\
\text { exemplares } \\
\left(6^{\circ} \text { ano }\right)\end{array}$ \\
\hline $1^{\circ}$ & $\begin{array}{c}\text { História, } \\
\text { Sociedade e } \\
\text { Cidadania }\end{array}$ & $\begin{array}{c}\text { Editora } \\
\text { FTD }\end{array}$ & Alfredo Boulos Júnior & 923.792 \\
\hline $2^{\circ}$ & Projeto Araribá & $\begin{array}{c}\text { Editora } \\
\text { Moderna }\end{array}$ & $\begin{array}{c}\text { Maria Raquel } \\
\text { Apolinário }\end{array}$ & 478.724 \\
\hline $3^{\circ}$ & $\begin{array}{c}\text { Vontade de } \\
\text { Saber }\end{array}$ & $\begin{array}{c}\text { Editora } \\
\text { FTD }\end{array}$ & $\begin{array}{c}\text { Adriana Dias; Keila } \\
\text { Grinberg; Marco } \\
\text { Pellegrini }\end{array}$ & 315.013 \\
\hline $4^{\circ}$ & Projeto Mosaico & $\begin{array}{c}\text { Editora } \\
\text { Scipione }\end{array}$ & $\begin{array}{c}\text { Claudio Vicentino; José } \\
\text { Bruno Vicentino }\end{array}$ & 288.248 \\
\hline $5^{\circ}$ & Historiar & Editora & $\begin{array}{c}\text { Gilberto Cotrim; Jaime } \\
\text { Saraiva }\end{array}$ & 219.441 \\
\hline
\end{tabular}

Fonte: FNDE. Tabela sistematizada por Aragão, 2019. Disponível em:

http://www.fnde.gov.br/programas/programas-do-livro/livro-didatico/dados-estatisticos.

\footnotetext{
2 Através do EDITAL DE CONVOCAÇÃO 02/2015 - CGPLI PNLD 2017 ocorreu o processo de inscrição e avaliação de obras didáticas para o PNLD. Houve a convocação de editores para o processo de aquisição de obras didáticas destinadas aos estudantes e professores dos anos finais do ensino fundamental das escolas públicas federais e as que integram as redes de ensino estaduais, municipais e do Distrito Federal, participantes do PNLD. O resultado da aprovação foi publicado pela portaria № 13, de 23 de junho de 2016. O PNLD aprovou 14 coleções de História para os anos 2017, 2018 e 2019.
} 
Os números (coluna quantidade de exemplares) demonstram que os livros eleitos como fonte de pesquisa possuem um número significativo de acesso de crianças brasileiras. Para entender o tamanho dessa representatividade, basta observar os números do PNLD - 2017-2019. Para o triênio 2017-2019, o Programa aprovou 14coleções para a área de História, cada coleção é composta por quatro volumes, e cada volume volta-se para uma fase do Ensino Fundamental (anos finais). No processo de seleção realizado pelas escolas públicas, encontram-se cinco coleções mais distribuídas pelo FNDE, conforme tabela acima, o que perfaz um total de 2.225,218 exemplares. Esses milhões de livros correspondem a quase $70 \%$ dos exemplares comprados/fornecidos. Logo, o nosso estudo se concentra nestas cinco obras, pela grande quantidade de crianças alcançadas num país de dimensões continentais feito o Brasil (Tabela 2):

Tabela 2 - Coleções mais distribuídas do Ensino Fundamental (anos finais, $6^{\circ}$ ano)

\begin{tabular}{|c|c|c|}
\hline Colocação & $\begin{array}{c}\text { Quantidade de exemplares } \\
\left(6^{\circ} \text { ano }\right)\end{array}$ & $\begin{array}{c}\text { Percentual de distribuição } \\
\text { para as escolas }\end{array}$ \\
\hline $1^{\circ}{\text { ao } 5^{\circ}}^{\circ}$ & 2.225 .218 & $68 \%$ \\
\hline $6^{\circ}$ ao $14^{\circ}$ & 718,498 & $32 \%$ \\
\hline
\end{tabular}

Fonte: FNDE. Tabela sistematizada por Aragão, 2019. Disponível em:

http://www.fnde.gov.br/programas/programas-do-livro/livro-didatico/dados-estatisticos.

Selecionadas as coleções para análise, fizemos um novo recorte, para nos aproximarmos do problema de investigação: os usos do conceito de Pré-história nos livros didáticos.

Na cultura escolar, o debate sobre o conceito de História e a Pré-história aparece no currículo do $6^{\circ}$ ano, mais particularmente, nos primeiros capítulos do livro didático. No campo metodológico, realizamos análise de conteúdo nos textos das cinco coleções selecionadas para estudo. A abordagem qualitativa se adequa melhor ao estudo proposto, pois permite explorar aspectos do ensino e da aprendizagem, como, por exemplo, a construção das relações de saber contidas nos conceitos analisados nos livros didáticos. Esse tipo de pesquisa, nas Ciências Sociais, se ocupa, como afirma Minayo, com: "um nível de realidade que não pode ou não deveria ser quantificado. Ou seja, ela 
trabalha com o universo dos significados, dos motivos, das aspirações, das crenças, dos valores e das atitudes" (MINAYO, 2010, p. 21).

Jurandir Malerba (2006) nos ensina que o historiador tem à sua disposição uma “maquinaria conceitual” que é o produto dos métodos de pesquisa e reflexão histórica de extensão secular, que revela o percurso do pensamento histórico e da própria disciplina História (MALERBA, 2006, p. 11-12). A construção dos sentidos historiográficos produzidos em diferentes épocas, que é aperfeiçoada pelos historiadores. Esse mecanismo permite sistematizar e analisar o passado por diferentes visões historiográficas. Tal relação está presente no livro didático de História, como aborda Flávia Caimi (2002). Para a autora, a produção didática brasileira não está alheia às discussões no campo teórico e historiográfico que se travam no âmbito nacional e internacional. O livro didático assimila em maior ou menor grau as perspectivas e as transformações que ocorrem na academia, no mercado editorial, nas pós-graduações (CAIMI, 2002, p. 77).

Para entender o processo de construção do conceito de Pré-história e o seu lugar no livro didático brasileiro é preciso observar as diferentes acepções do termo história ao longo do tempo. Definir o que é história representa uma operação teórico-política capaz de construir narrativas sobre lugares, pessoas, objetos e tempos. Por isso, realizar o exercício proposto por Reinhart Koselleck, chamado de História dos Conceitos, permite acompanhar as ressignificações da palavra, já que o vocábulo que designa o conceito permanece igual, o que muda é a perspectiva em relação a ele.

Para Koselleck, a atividade historiográfica se apresenta nos seguintes termos: "Ou ele (historiador) analisa fatos que já foram anteriormente articulados na linguagem ou então, com a ajuda de hipóteses e métodos, reconstrói fatos que ainda não chegaram a ser articulados, mas que ele revela a partir desses vestígios" (KOSELLECK, 2006, p. 305). Então, o historiador lida com expressões e conceitos de uma época, reflete sobre tais conceitos, indaga-os ou, a partir de sua atividade científica de pesquisa, pode elaborar uma nova conceituação. Isso quer dizer: novos conceitos podem ser criados ou usados a partir de uma tradição já posta e construída pelos historiadores. 
Logo, o termo Pré-história, embora, remeta-nos diretamente a um debate do século XIX, cuja definição de história estava estreitamente ligada às populações que possuíam a escrita como código cultural, passará por ressignificações que precisam ser observadas. Na literatura, encontramos indícios de que o termo Pré-história apareceu pela primeira vez no livro The Archaeology and Prehistoric Annals of Scotland (1851), cujo autor, o inglês Daniel Wilson, define a Pré-história "como um estudo relacionado a períodos ou tipos de dados históricos, cujo registro não fora intencional” (TRIGGER, 1973, p. 4).

O conceito surge em contraposição à ideia de uma cronologia bíblica; não se tratava apenas de debates técnicos sobre datações, escavações, mas um debate entre arqueólogos evolucionistas e os criacionistas (concepção religiosa) sobre a origem dos seres humanos na terra. Segundo Gosden:

A Pré-história representa um campo de batalha para diferentes visões de mundo: os arqueólogos vislumbrando um passado de 6 milhões de anos para nossos primeiros ancestrais humanos, os criacionistas negando a existência de qualquer Pré-história, já que toda nossa existência é abrangida do Gênesis em diante. (GOSDEN, 2012, p. 27)

A ideia construída acerca do termo Pré-história foi a de revelar que as tecnologias industriais complexas (do século XIX-XX) tiveram seus primórdios em tempos remotos da humanidade e o próprio paleolítico dava testemunho material desse avanço gradual da capacidade humana, tanto de evoluir quanto de dominar o meio ambiente. O "homem evoluído" domina a ciência, resta apenas criar mecanismos de diferenciação deste homem em relação aos demais. É nesse sentido que se verifica a construção de uma lógica que perpassa o século XX e se ramifica no século XXI, sempre atrelando o conceito de Pré-história a justificativas científicas da superioridade europeia comparada aos povos da América, África, Oceania.

$\mathrm{Na}$ arqueologia, no século XX, havia uma defesa de que a evolução da cultura material determinava também o aprimoramento social e moral de um povo, o evolucionismo cultural. A ideia de progresso industrial e tecnológico é respaldada pela 
ciência positivista. Com isso se defende que a humanidade atravessa estágios sucessivos. Uma lógica evolucionista e etnocêntrica começa a ser construída sob o discurso da racionalidade, do progresso e do desenvolvimento tecnológico. Os seres humanos cumpririam o estágio evolutivo: selvageria, passando para a barbárie até chegar à civilização. O estágio civilizatório é identificado com a criação da escrita como um marco tecnológico (TRIGGER, 2004, p. 106).

Essa ideia baseada no modelo evolutivo que culmina com a criação e desenvolvimento da escrita, embora criticada, perdura no século $\mathrm{XX}$, e ainda circula no século XXI. Para observarmos essa influência, apresentamos a definição que consta no Dicionário de Arqueologia, em que Alfredo Mendonça de Souza traz a seguinte ideia sobre o conceito de Pré-história:

Em seu sentido restrito, a História é a narração dos feitos humanos através dos testemunhos escritos, mas o conhecimento desses feitos pode ser obtido por outros meios, como faz a arqueologia. O termo Préhistória foi cunhado para designar a história do homem anterior ao aparecimento dos documentos escritos. (SOUZA, 1990, p. 103-104)

Paul Bahn, no Dictionary of Archaeology, faz a distinção entre período préhistórico e período histórico:

Período Pré-histórico ou Pré-História: Qualquer período para o qual não haja evidência documental contemporânea. Constitui o principal segmento do passado humano e é o principal estudo em arqueologia. (BAHN, 2004, p. 393, tradução nossa) ${ }^{3}$

Período histórico: Qualquer período no passado que possa ser estudado usando documentos escritos contemporâneos. (BAHN, 2004, p. 205, tradução nossa) $)^{4}$

\footnotetext{
3 Prehistoric period or Prehistory: Any period for which there is no contemporary documentary evidence. It constitutes the major segment of the human past, and is the major study in archaeology. (BAHN, 2004, p. 393).

${ }^{4}$ Historic period: Any period in the past that can be studied by using contemporary written documents. (BAHN, 2004, p. 205).
} 
Com relação aos sentidos atribuídos ao termo Pré-história, observamos que, a partir do século XIX, o termo representa: a) período da História em que não há evidência de documentos escritos; b) período da História com extensa temporalidade e c) período da História com fonte de estudo para Arqueologia.

Para entender como a historiografia escolar dialoga com a historiografia acadêmica, analisamos alguns elementos que são fundamentais, como os termos historiografia, periodização e fonte. A intenção é entender os sentidos que o termo Préhistória possui. Para análise das coleções, utilizaremos a metodologia de análise de conteúdo de Bardin (2010), que consiste em um conjunto de técnicas de análise que busca fazer a descrições de conteúdos de mensagens, de dados indicadores (quantitativos ou não) que ao serem analisados permitam fazer inferências de tais mensagens (BARDIN, 2010, p. 38).

A primeira categoria que criamos para análise foi a terminologia, já que no exercício proposto, em história do conceito, o vocabulário deve ser observado. Observase que a terminologia usada pelos livros didáticos para se referir ao período anterior à escrita é PRÉ-HISTÓRIA. O termo Pré-história nos livros didáticos é apresentado como um conceito que precisa ser problematizado, haja vista os argumentos apresentados pelos autores:

A periodização mais utilizada em livros de história foi criada por estudiosos europeus. Eles dividiram a história em cinco grandes períodos: Pré-história, História Antiga, História Medieval, História Moderna e História Contemporânea. Muitos estudiosos criticam essa divisão por ela levar em consideração apenas os acontecimentos da história europeia e anular a história dos outros povos (APOLINÁRIO, 2014 p. 28, grifo nosso)

Muitos estudiosos criticam essa divisão tradicional da História por diversos motivos. Primeiro, porque essa divisão valoriza fatos importantes para os povos da Europa e desconsidera o que se passava, por exemplo, na África ou na Ásia. Segundo, porque ainda há povos que não utilizam a escrita, o que não quer dizer que não possuam uma história. (BOULOS JUNIOR, 2015 p. 40, grifo nosso)

HAVIA HISTÓRIA ANTES DA HISTÓRIA?

A expressão "Pré-história" quer dizer anterior à História (Pré = antes). Ela indica o enorme período compreendido entre o aparecimento dos 
seres humanos sobre a terra (há mais de 5 milhões de anos) e o surgimento da escrita [...] Isso significa que todo período anterior ao surgimento da escrita não seria considerado parte da História.

Mas por que a invenção da escrita foi escolhida como marco inicial da História? Há cerca de 200 anos os historiadores se baseavam nos textos escritos pelos povos antigos para entender seu passado. Assim, acreditavam que os povos do passado que não possuíam escrita não poderiam ser estudados - e, portanto, não teriam uma história. Daí criaram a expressão "Pré-história" para denominar o período em que viveram esses povos que não dominavam a escrita.

Com o tempo, os historiadores descobriram que desenhos, moradias, e ferramentas deixados pelos povos pré-históricos também revelavam muito sobre seu passado. Ou seja, entenderam que era possível contar sua história utilizando documentos não escritos. Apesar disso, a expressão "Pré-História" continuou sendo usada para definir o período anterior à invenção da escrita (VICENTINO, 2016, p. 25)

Ao observar os sentidos atribuídos à palavra Pré-história no livro didático, notamos dois movimentos: alteração semântica e ampliação do conceito. No primeiro movimento, encontram-se livros didáticos que estão em fase de transição, ou seja, livros que estão usando apenas o termo História ou períodos históricos (BOULOS JUNIOR, 2015). No segundo movimento, notam-se os livros didáticos que trazem o conceito expresso em suas páginas, justificando que se trata de uma periodização tradicional, mas identificam no termo e no uso da periodização algo atrasado e etnocêntrico (APOLINÁRIO, 2014).

De modo geral, o debate levantado pelos livros didáticos demonstra que a presença do termo Pré-história do livro tem uma função política, sobretudo, por explorar como a historiografia oitocentista/eurocêntrica categorizava de forma preconceituosa as sociedades consideradas "sem Estado", no caso, os grupos populacionais americanos, africanos e asiáticos. Por muito tempo, o termo Pré-história foi empregado para definir um grupo social estigmatizado como "primitivo" (CORRÊA, 2013, p. 26). No Brasil, a história e a arqueologia herdaram essa concepção de Pré-história formulada no século XIX, que ganhará reforço no século XX com a historiografia francesa quando associou o período às populações ágrafas (CORRÊA, 2013, p. 26). 
Nos últimos anos, a leitura histórica e arqueológica sobre esse período longínquo do passado dos seres humanos, nas diferentes partes do território, vem sendo modificada. Para Ângelo Corrêa, essa mudança acontece pela influência exercida pelo método histórico no campo da arqueologia, que aos poucos substitui, no Brasil, o termo pré-histórico por pré-colonial. Na arqueologia, essa mudança é “reflexo das críticas modernas, que advogam a favor de uma arqueologia menos colonizadora, identificando os vestígios arqueológicos americanos com antepassados das sociedades atuais" (CORRÊA, 2013, p. 27).

Logo, ao se explicar no livro didático que o termo Pré-história esteve relacionado a sociedades que não possuíam escritas e aos povos primitivos, seguido de uma explicação crítica para os usos desses mesmos, o material chama atenção para a necessidade de considerarmos todas as populações como portadoras de culturas e de história, pois, todos os seres humanos são capazes de representar o mundo com símbolos (FUNARI, 2013, p. 24). Dessa forma, no quadro 1, observa-se que as expressões que definem o termo Pré-História, precisam ser contextualizadas e problematizadas, já que isoladas simbolizam a ideia de povos primitivos e sem escrita:

Quadro 1- Terminologia

\begin{tabular}{|c|c|c|}
\hline Coleção (livro) & Categoria & Pré-história \\
\hline $\begin{array}{l}\text { História, Sociedade e } \\
\text { Cidadania }\end{array}$ & \multirow{5}{*}{ Terminologia } & $\begin{array}{l}\text { "Divisão tradicional da História"; "fatos } \\
\text { "importantes para os povos da Europa"; "há } \\
\text { povos que não utilizam a escrita". p.40 }\end{array}$ \\
\hline Projeto Araribá & & $\begin{array}{l}\text { "A periodização mais utilizada em livros de } \\
\text { história foi criada por estudiosos europeus"; } \\
\text { "anula a história de outros povos". p.28 }\end{array}$ \\
\hline Vontade de Saber & & O livro não faz uso do termo Pré-história. \\
\hline Projeto Mosaico & & $\begin{array}{l}\text { "não desenvolveram a escrita"; "divisão"; } \\
\text { "invenção da escrita"; "atrasados"; } \\
\text { "primitivos".p.25 }\end{array}$ \\
\hline Historiar & & $\begin{array}{l}\text { "atividade cultural" } \\
\text { "etnocentrismo" "escrita"; "tradicional". p.40 }\end{array}$ \\
\hline
\end{tabular}

Fonte: ARAGÃO, 2019, p. 75 
Após analisar o termo e suas possíveis variantes, analisamos a adequação conceitual, que é vista com a relação de sentido, de pertinência e relevância de um texto para articular os argumentos de um dado tema. Logo, buscamos observar se o debate levantado pelo termo Pré-História nos livros didáticos tinha pertinência para formação intelectual e cultural das crianças.

O sistema de periodização clássica utilizado no campo da história é uma criação francesa do século XIX que será seguida, no Brasil, pelos livros didáticos e pela literatura acadêmica. Esse sistema estabeleceu uma distinção entre os que possuíam história e os que não possuíam (Pré-história e História Antiga, Medieval, Moderna e Contemporânea). Já o sistema de periodização usado no campo da arqueologia é diferente do proposto pelos teóricos do campo da História no século XIX. A arqueologia que se dedicará a estudar as sociedades europeias no período pré-histórico usará os pressupostos de Thomsem, Lubbock e Mortillet, que organizam o tempo em estágios: Paleolítico, Idade da Pedra ou Idade dos Metais. Cabe ressaltar que esses pressupostos só devem ser utilizados para observar a realidade europeia, pois, o sistema de periodização da arqueologia americana foi desenvolvido em 1958, por Gordon Willey e Philip Phillips, que estabeleceram os estágios a partir de critérios econômicos e cronológicos: Paleoíndio, Arcaico e Formativo (NEVES, 1995, p. 176-177).

Embora, os arqueólogos estejam difundindo os pressupostos da arqueologia americana desde os anos 1990 (FUNARI, 2013), observamos que nas narrativas dos livros didáticos acerca da cultura material e dos estágios cronológicos do período Pré-histórico não há uma distinção entre os estágios pré-históricos no continente europeu e americano. Os livros didáticos estudados trazem situações, artefatos e imagens de diferentes localidades (Brasil, Argentina, Itália e Grécia) sem observar as peculiaridades semânticas e temporais (Quadro 2). 
Quadro 2 - Adequação conceitual

\begin{tabular}{|c|c|c|}
\hline Coleção (livro) & Categoria & Pré-história \\
\hline $\begin{array}{l}\text { História, Sociedade } \\
\text { e Cidadania }\end{array}$ & \multirow[t]{5}{*}{$\begin{array}{l}\text { Adequação } \\
\text { conceitual }\end{array}$} & $\begin{array}{l}\text { "História e conhecimento } \\
\text { Para construir um conhecimento sobre determinado povo ou } \\
\text { episódio, o historiador necessita do saber elaborado pelos } \\
\text { profissionais de outras áreas, como os arqueólogos, os } \\
\text { geógrafos, os biólogos, entre outros. Os arqueólogos estudam } \\
\text { os grupos humanos por meio dos vestigios materiais deixados } \\
\text { por eles, como restos de casas, instrumentos de trabalho, } \\
\text { pinturas feitas em rochas e vasos. O pedaço de um machado } \\
\text { de pedra escaavado por um arqueólogo e examinado em } \\
\text { laboratório pode nos contar sobre a idade daquela pedra } \\
\text { e o modo de vida do povo que utilizou aquele machado. } \\
\text { Vasos, potes e jarros para beber água estão entre os achados } \\
\text { mais comuns nas escavaçóes arqueológicas; porém, são } \\
\text { poucos os encontrados inteiros. } \\
\text { Assim, incorporando os saberes acumulados por outros } \\
\text { estudiosos, o historiador vai aumentando seu conhecimento } \\
\text { sobre os seres humanos e sua trajetória ao longo do tempo." } \\
\text { p.19 }\end{array}$ \\
\hline Projeto Araribá & & $\begin{array}{l}\text { "Para muitos pesquisadores, a história teve início quando } \\
\text { os hominídeos começaram a fabricar, de maneira regular, } \\
\text { utensílios de pedra com um formato e uma intenção } \\
\text { determinada." } \\
\text { "Ao estudar o passado primitivo da história humana, os } \\
\text { pesquisadores deram o nome de Paleolitico" } \\
\text { "Aproximadamente } 12 \text { mil anos atrás, iniciou-se também uma } \\
\text { mudança na fabricação de instrumentos. Os grupos humanos } \\
\text { começaram a produzir enxadas, foices, pilōes e machados } \\
\text { com pedras polidas, inaugurando o periodo que os estudiosos } \\
\text { denominaram Neolítico" p. } 43 \text { e } 46 \text {. }\end{array}$ \\
\hline Vontade de Saber & & $\begin{array}{l}\text { "Os seres humanos passaram por grandes transformações } \\
\text { fisicas e culturais durante os periodos paleolitico e neolitico"; } \\
\text { "Costuma-se utilizar as técnicas de fabricação de ferramentas } \\
\text { como elemento de separação entre os periodos históricos } \\
\text { chamados Paleolítico e Neolitico." p.41. }\end{array}$ \\
\hline Projeto Mosaico & & $\begin{array}{l}\text { "Havia história antes da história? } \\
\text { A expressão "Pré-história" quer dizer anterior à História } \\
\text { (pré=antes). Ela indica o enorme período compreendido entre } \\
\text { o aparecimento dos seres humanos sobre a terra (há mais de } \\
5 \text { milhões de anos) e o surgimento da escrita, que, em alguns } \\
\text { lugares, ocorreu no final do quarto milênio antes de cristo. Isso } \\
\text { significa que todo o periodo anterior ao surgimento da escrita } \\
\text { não seria considerado parte da História. } \\
\text { Há cerca de } 200 \text { anos os historiadores se baseavam nos } \\
\text { textos escritos pelos povos antigos para entender seu } \\
\text { passado. Assim, acreditavam que os povos do passado que } \\
\text { não possuiam escrita não poderiam ser estudados - e, } \\
\text { portanto, não teriam história. Daí criaram a expressão "Pré- } \\
\text { história" para denominar o periodo em que viveram esses } \\
\text { povos que não dominavam a escrita. } \\
\text { Com o tempo, os historiadores descobriram que desenhos, } \\
\text { moradias e ferramentas deixados pelos povos pré-históricos } \\
\text { também revelavam muito sobre seu passado. Ou seja, } \\
\text { entenderam que era possivel contar sua história utilizando } \\
\text { documentos não escritos. Apesar disso, a expressão "Pré- } \\
\text { história" continuou sendo usada para definir o periodo anterior } \\
\text { à invenção da escrita." p.25 }\end{array}$ \\
\hline Historiar & & $\begin{array}{l}\text { "Atualmente, os estudiosos não dão uma importância tão } \\
\text { grande para essa distinção entre fontes escritas e não } \\
\text { escritas. Para eles, há várias formas de registro do } \\
\text { passado humano que podem ser interpretadas } \\
\text { historicamente. Além disso, o ser humano, desde que } \\
\text { surgiu na Terra é sempre um ser histórico. Apesar de } \\
\text { críticas mais recentes, o termo "Pré-história" continua } \\
\text { sendo usado para referir-se ao periodo inicial da } \\
\text { existência humana sobre a Terra. Neste livro também, } \\
\text { eventualmente, podemos nos referir a esse termo - } \\
\text { sabendo que esse período faz parte da História como } \\
\text { todos os outros." p.40 e } 41\end{array}$ \\
\hline
\end{tabular}

Fonte: ARAGÃO, 2019, p. 80 
Ao fazer o exercício analítico da adequação conceitual do termo Pré-história, percebe-se que os livros trazem divisões que por muito tempo representaram e ainda representam períodos da Pré-história, como Paleolítico, Neolítico e Idade dos Metais. Alguns livros dão notoriedade ao trabalho dos arqueólogos na pesquisa dos períodos mencionados acima, principalmente, nos estudos dos agrupamentos humanos e na produção da cultura material por povos antigos. Contudo, se nos detivermos nos trechos dos livros, perceberemos algumas passagens dignas de críticas.

Por exemplo, o livro Projeto Araribá (Moderna) menciona que "Ao estudar o passado primitivo da história humana, os pesquisadores deram o nome de Paleolítico". Esse trecho está elencado no quadro 2. Percebe-se, então, a substituição do termo Préhistória por uma associação a um passado primitivo. É justamente essa criação de um homem primitivo, um homem antigo, atrasado, que perpassa sutilmente através dos livros didáticos e reproduz veladamente estereótipos e preconceitos.

Os cinco livros pesquisados "rejeitam” o termo Pré-história. O argumento mais utilizado pelos autores é julgarem-no inadequado. O livro Projeto Mosaico (Scipione) questiona o termo: "Havia história antes da história? A expressão "Pré-história” quer dizer anterior à História (pré = antes)." "Ela indica o enorme período compreendido entre o aparecimento dos seres humanos sobre a terra (há mais de 5 milhões de anos) e o surgimento da escrita", texto elencado no quadro 2 acima. Em contrapartida, o livro propõe um exercício reflexivo ao afirmar que essa divisão escrita/ não escrita vem do século XIX, período no qual os historiadores privilegiavam os documentos escritos.

Dando continuidade à ideia trazida no livro Projeto Araribá, criou-se a expressão povos pré-históricos para designar os povos sem escrita; segundo o livro, o conceito permaneceu, mesmo depois que os historiadores perceberam que o domínio da grafia não era determinante, isto é, não impedia de se contar uma História dos povos sem escrita, na atualidade.

Mas, ao mesmo tempo em que existe a "negação" do termo, os livros trazem explicações e divisões atreladas a esse período histórico. É o exemplo do livro Historiar (Saraiva), que segue o mesmo raciocínio posto há pouco, afirmando que os estudiosos 
não dão importância para essa distinção entre fontes escritas e não escritas e que há várias formas de registros e interpretações do passado humano; contudo, o termo Préhistória continua sendo usado para se referir ao período inicial da existência humana. O livro diz que o termo pode ser usado eventualmente.

Em síntese, os livros trazem as divisões mais tradicionais da Pré-história (Paleolítico, Neolítico e Idade dos Metais), que são voltadas para analisar o contexto europeu. Logo, nos livros se faz a crítica ao termo - há livros que nem mencionam o vocábulo, como Vontade de Saber (FTD), por exemplo -, mas fazem uso da periodização tradicional e eurocêntrica que exclui povos originários, por exemplo, no continente americano. Os livros mostram as inadequações inerentes ao termo Pré-história, entretanto justificam o uso do termo pela força da tradição da Cultura Escolar.

\section{Historiografia escolar e historiografia acadêmica: organizando a} periodização dos livros de história

Analisar os livros na tentativa de observar se trazem consigo uma perspectiva historiográfica atualizada envolve novos olhares sob os conteúdos abordados. Uma narrativa inovadora e atualizada conecta-se ao diálogo, ao respeito, à cultura de paz, à formação cidadã, à inclusão das minorias e aos princípios soberanos da democracia. Entender a pluralidade dos espaços, dos tempos e dos processos históricos faz parte de uma perspectiva que inova na forma de assimilar os processos históricos. No ensino de História não cabe mais uma memorização fatigante e somativa dos conteúdos. É preciso levar o aluno a operar com informações, compreender argumentos, debater lógicas argumentativas e perceber as singularidades dos acontecimentos e processos históricos na dimensão e na mudança temporal em que ocorrem.

Nesse sentido, os livros didáticos voltados para o $6^{\circ}$ ano, ao abordarem a PréHistória, trazem aspectos ligados a elementos da cultura, história e economia dos diferentes povos estudados. Essas questões abordadas são influenciadas pela renovação das pesquisas arqueológicas ao operar com conceitos "introduzidos pelos [arqueólogos] pós-processualistas, que trouxeram a noção de habitus de Pierre Bourdieu e a gramática 
generativa de Noam Chomsky [...], substituindo a preocupação apenas com os processos e comportamentos para também considerar contingência e agência" (COSTA, 2013, p. 30). Para Costa, "o pós-processualismo5, por sua vez, surge na década de 1980 na Inglaterra e vai encontrar no estudo do pensamento, e não só da cultura material, sua principal motivação para a investigação arqueológica" (COSTA, 2013, p. 30).

Para entender, essa inovação historiográfica na forma de ler o tempo, basta observar a ênfase dada aos aspectos culturais, conforme quadro 3:

\section{Quadro 3 - Inovação Historiográfica (atualização)}

\begin{tabular}{|c|c|c|}
\hline Coleção (livro) & Categoria & Pré-história \\
\hline $\begin{array}{l}\text { História, } \\
\text { Sociedade e } \\
\text { Cidadania }\end{array}$ & & $\begin{array}{l}\text { "[...] As culturas são diferentes entre si; apenas isso. } \\
\text { Cada cultura tem o seu valor e não há uma cultura } \\
\text { superior a outra. Conforme a Antropologia, nenhum } \\
\text { povo pode ser chamado de "selvagem" ou "primitivo" } \\
\text { porque se veste, se enfeita, se alimenta ou pensa } \\
\text { diferente do outro." p. } 29\end{array}$ \\
\hline Projeto Araribá & & $\begin{array}{l}\text { "Muitos estudiosos criticam esse divisão por levar } \\
\text { em consideração apenas acontecimentos da história } \\
\text { europeia e anular a história de outros povos" p. } 28 \text {. }\end{array}$ \\
\hline $\begin{array}{c}\text { Vontade de } \\
\text { Saber }\end{array}$ & $\begin{array}{l}\text { Inovação } \\
\text { Historiográfica } \\
\text { (atualização) }\end{array}$ & $\begin{array}{l}\text { "Arqueologia } \\
\text { A Arqueologia é uma área do conhecimento que estuda } \\
\text { o modo de vida dos povos do passado por meio da } \\
\text { análise dos vestígios materiais por eles produzidos. } \\
\text { Muito do que sabemos sobre a Antiguidade, por } \\
\text { exemplo, se deve ao trabalho dos arqueólogos." p.26 }\end{array}$ \\
\hline $\begin{array}{l}\text { Projeto } \\
\text { Mosaico }\end{array}$ & & $\begin{array}{l}\text { "A divisão entre Pré-história e História deu origem a } \\
\text { algumas ideias falsas. Uma delas é a de que no } \\
\text { período anterior à invenção da escrita a humanidade } \\
\text { não tinha história. A outra é a de que os povos que } \\
\text { não desenvolveram a escrita são todos pré- } \\
\text { históricos - incluindo os que ainda hoje habitam } \\
\text { diversas partes do planeta, como grupos indigenas } \\
\text { brasileiros, certos povos africanos e australianos. } \\
\text { Em consequência disso, a expressão "Pré-História" } \\
\text { algumas vezes é usada de forma errada, ou seja, para } \\
\text { qualificar povos ou pessoas como atrasados e } \\
\text { inferiores por não terem desenvolvido a mesma } \\
\text { cultura e tecnologia que outros. p.25 }\end{array}$ \\
\hline
\end{tabular}

5 Os arqueólogos pós-processualistas levam em consideração os significados simbólicos e o contexto cultural de suas descobertas. Para compreender a cultura material é necessário estabelecer uma relação com a sociedade que a utilizou “[...] os arqueólogos são obrigados a examinar o contexto histórico específico de cada cultura. Assim, há uma reaproximação da arqueologia com a história” (SYMANSKI, 1997, p. 31). 


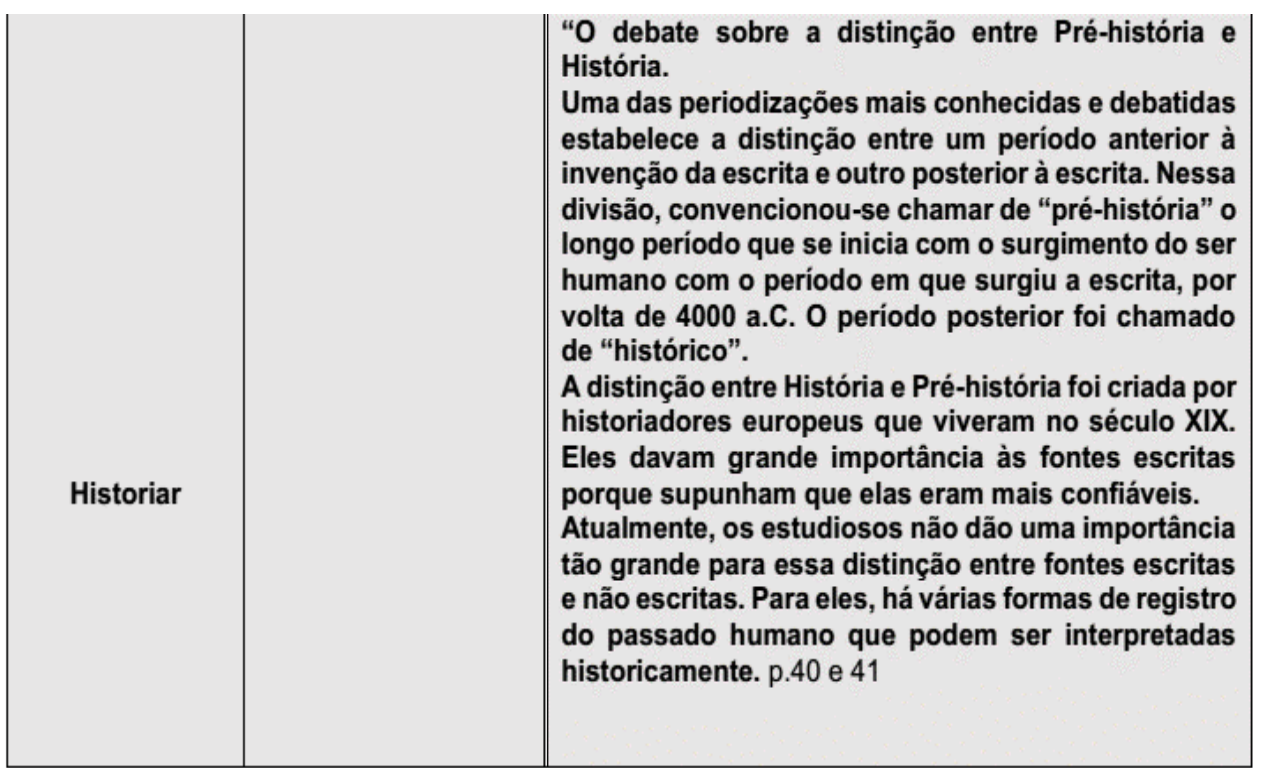

Fonte: ARAGÃO, 2019, p. 87

Então, procurar aspectos inovadores nas coleções didáticas perpassa pela identificação de narrativas que contemplem os sentidos que as mudanças geram nas sociedades, observar a duração própria de cada momento histórico, os espaços e as pessoas envolvidas no processo, o contexto, as dimensões políticas, culturais e econômicas associadas à ideia de embates decorrentes de fatores que permanecem ou que mudam de acordo com as transformações históricas. Nota-se que as cinco coleções apresentaram perspectivas atualizadas sobre o conceito de História. A inovação consiste em trazer os elementos que dão sentido à História, como os sujeitos, a forma de pensar a construção histórica atualmente e a relação teórica que se estabelece.

Os livros História, Sociedade e Cidadania (FTD), Projeto Araribá (Moderna), Vontade de Saber (FTD) e Projeto Mosaico (Scipione) apontam como sujeitos da História as mais diversas denominações e grupos sociais, como artesãos, soldados, generais, reis, presidentes, idosos, crianças, pobres, ricos etc. e também nos espaços onde a História é produzida (nas instituições como: Igreja, Câmara dos Deputados, Exércitos etc.). O diálogo da História com esses diversos atores e em diferentes cenários representa uma atualização historiográfica: deslocam-se as concepções mais antigas da História, nas quais 
o sentido da narrativa histórica partia da ótica dos que exerciam diretamente a dominação para valorizar o papel histórico de outras instâncias sociais - pobres, mulheres, dentre tantas outras categorias que por muito tempo foram escamoteadas da História oficial.

Os livros também abordam a possibilidade de os acontecimentos históricos serem vistos por diferentes ângulos, gerando diferentes interpretações e mais de uma versão para as narrativas construídas, em oposição a uma história única, linear e de verdade absoluta que predomina nos livros didáticos de história até os anos 1980. Nos livros (atuais), e entre os historiadores, existe uma ideia muito forte de que não se produz mais história por esse caminho.

Já o livro Historiar (Saraiva) aborda a construção do sentido da história em tempos diversos. Foi o único que trouxe uma visão mais contextualizada do conceito de História, permitindo que o aluno possa perceber os regimes de historicidades contidos no conceito ao longo de sua construção.

Os livros História, Sociedade e Cidadania (FTD) e Projeto Araribá (Moderna), em relação à Pré-história, trazem uma visão com pequenas atualizações. O primeiro faz referência à cultura como fator de diferenciação entre os povos. Isso constitui uma crítica às narrativas históricas que conservam a ideia de superioridade e inferioridade entre povos. O livro faz uma reflexão em torno do termo "selvagem" e "primitivo", pois, por princípios antropológicos atuais que levam em conta o contexto histórico de cada cultura, nenhum povo deve ser denominado de selvagem em oposição ao status de civilizado, tal qual era no evolucionismo cultural. As diferenças são culturais. A inovação é no sentido de eleger as diferenças culturais como peculiaridades das diferentes sociedades e não mais como estágios civilizatórios.

A obra Vontade de Saber (FTD) tem como diferencial não apresentar o termo Préhistória em seu texto didático. Os livros Projeto Mosaico (Scipione) e Historiar (Saraiva), mesmo utilizando as divisões tradicionais, propõem um debate mais profundo sobre os dois termos, História e Pré-história: chamam de uma construção falsa a divisão de História 
e Pré-história em função da escrita, pois o período da humanidade anterior à invenção da escrita tem História por ser o período mais longo e antigo dos registros humanos.

A problemática mais inovadora identificada nas coleções didáticas em relação ao termo Pré-história tem a ver com a escrita. Nos livros, vêm à tona o debate e a crítica à classificação dos povos em pré-históricos por não terem desenvolvido um sistema de escrita. Outra crítica, que se apresenta nos livros Projeto Araribá (Moderna), Projeto Mosaico (Scipione) e Historiar (Saraiva), é ao conceito de Pré-história ser usado para qualificar povos e pessoas como inferiores em relação àqueles que não tivessem o mesmo nível de cultura e de tecnologia.

A comparação de diferentes culturas e diferentes avanços tecnológicos não é um fator científico válido para estabelecer uma relação de superioridade e inferioridade entre os povos. Os livros inovam em suas narrativas ao debaterem essa questão. Em síntese, os livros tratam a Pré-história como um termo atrelado a divisões da História que podem suscitar discriminação e uma visão errônea para com os povos mais antigos.

\section{Considerações finais}

Nos livros didáticos pesquisados, adotou-se a visão de que a História significa tanto o fato/acontecimento quanto sua reconstituição pelos historiadores. Nesse sentido, a História enquanto conceito significa o conhecimento advindo da produção intelectual do historiador mediado pelos métodos racionais e pelos instrumentos metodológicos de análises dos (das) documentos/fontes históricas e, como resultado desse processo, se alcançam verdades que são relativas e situadas historicamente no espaço-tempo. Disso advém o caráter dinâmico da ideia de História, pois a sistematização dos dados na História e da pesquisa histórica revelam mais um processo de construção do que algo inalterado, fixo e exato. A História, enquanto processo, é uma parte do conhecimento analisado e situado em determinado tema e período, atrelado a um sentido posto pela historiografia de sua época.

Quanto ao conceito de Pré-história, as definições encontradas nos livros didáticos fazem referência a uma periodização clássica que precisa ser problematizada, uma vez 
que, carrega consigo uma hierarquização dos grupos sociais. O conceito que é utilizado passou por ressignificações para o debate atual, embora seja um termo clássico, passível de muitas críticas, inclusive pelas coleções didáticas estudadas. Notamos que existe um movimento tímido de substituição do termo Pré-história, por expressões como História Indígena para se referir aos nossos primeiros habitantes; embora, especificamente, nos capítulos estudados não apareça o debate, nos capítulos posteriores, ao se reportar aos indígenas, utilizam-se, por exemplo, História Indígena ou ainda Pré-colonial.

A preocupação com o debate nos livros escolares sobre as teorias da História em linguagem didática não impediu de se ter uma argumentação qualitativa e de produzir uma narrativa atualizada sob muitos aspectos das tendências historiográficas. Ressalta-se que modificar paradigmas históricos ou lançar uma nova forma de escrever e perceber a História é algo que acontece paulatinamente. O mais importante foi perceber, nas coleções estudadas, que as visões históricas estão presentes nos livros e "mescladas entre si" para melhor compreensão da construção das narrativas historiográficas pelos alunos, mesmo diante de críticas como as observadas em relação ao termo Pré-história.

\section{Referências}

APOLINÁRIO, Maria Raquel. Projeto Araribá: história. 4.ed. São Paulo: Moderna. 2014.

ARAGÃO, Luiz Adriano Lucena. História e pré-história: investigando os usos desses conceitos nos livros didáticos de história. 2019. 154 f. Dissertação (Mestrado em História) - Universidade Federal Rural de Pernambuco, Recife. Disponível em: http://www.tede2.ufrpe.br:8080/tede2/handle/tede2/8391. Acesso em: 20 mar. 2020.

BOULOS JUNIOR, Alfredo. História, sociedade \& cidadania. 3.ed. São Paulo: FTD, 2015.

BAHN, Paul. Dictionary of archaeology. London: Penguin Books, 2004.

BARDIN, Laurence. Análise de conteúdo. Lisboa: Edições 70, 2010.

BITTENCOURT, Circe Maria Fernandes. Ensino de história: fundamentos e métodos. São Paulo: Cortez, 2011. 
BRASIL. LEI N 8.663, DE 14 DE JUNHO DE 1993. Revoga o Decreto-Lei nº 869, de 12 de dezembro de 1969, e dá outras providências. Diário Oficial da União: seção 1. Brasília, DF, p. 7885, 15 jun. 1993. Disponível em: https://www2.camara.leg.br/legin/fed/lei/1993/lei8663-14-junho-1993-374625-publicacaooriginal-1-pl.html. Acesso em: 12 jan. 2021.

CAIMI, Flávia Eloisa. O livro didático no contexto de transição dos paradigmas da História. In: CAIMI, Flávia Eloisa; MACHADO, Ironita A. P.; DIEHL, Astor Antônio (org.) O livro didático e o currículo de história em transição. Passo Fundo: UPF, 2002, p. 77-111.

CAIMI, Flávia Eloisa. O que sabemos (e o que não sabemos) sobre o livro didático de história: estado do conhecimento, tendências e perspectivas. In: GALZERANI, Maria Carolina Bovério; BUENO, João Batista Gonçalves; PINTO JR, Arnaldo. Paisagens da pesquisa contemporânea sobre livro didático de história. Campinas: UNICAMP, 2013. p. 35-52.

CHAUÍ, Marilena. Prefácio: história a contrapelo. In: DECCA, Edgar S. 1930: o silêncio dos vencidos. São Paulo: Brasiliense, 1986.

CHOPPIN, Alain. História dos livros e das edições didáticas: sobre o estado da arte. Educação e Pesquisa, São Paulo, v. 30, n. 3, p. 549-566, 2004.

CORRÊA, Ângelo Alves. Longue Durée: história indígena e arqueologia. Cienc. Cult., São Paulo, v. 65, n. 2, p. 26-29, Jun. 2013.

COSTA, Diogo M. Algumas abordagens teóricas na arqueologia histórica brasileira. Cienc. Cult., São Paulo, v. 65, n. 2, p. 30-32, Jun. 2013.

FNDE. Fundo Nacional de Desenvolvimento da Educação. Programas do Livro. Brasília: MEC, 2017. Disponivel em: http://www.fnde.gov.br/programas/programas-do-livro/livrodidatico/dados-estatisticos. Acesso em: 12 maio 2017.

FREITAS, Itamar. Livro didático de história: definições, representações e prescrições de uso. In: OLIVEIRA, Margarida Dias de; OLIVEIRA, Almir Flélix Bueno de. Livros didáticos de História: escolhas e utilizações. Natal: Editora da UFRN, 2009. p. 11-19.

FUNARI, Pedro Paulo A. Arqueologia no Brasil e no mundo: origens, problemáticas e tendências. Cienc. Cult., São Paulo, v. 65, n. 2, p. 23-25, Jun. 2013.

FONSECA, Selva Guimarães. Didática e prática de ensino de história: experiências, reflexões e aprendizados. 13. ed. São Paulo: Papirus, 2012. (Coleção Magistério: Formação e Trabalho Pedagógico).

GOSDEN, Chris. Pré-história. Porto Alegre: L\&PM POCKET, 2012. 
KOSELLECK, Reinhart. Futuro passado: contribuição à semântica dos tempos históricos. Rio de Janeiro: Contraponto, 2006.

MALERBA, Jurandir. A história escrita: teoria e história da historiografia. São Paulo: Contexto, 2006.

MINAYO, Maria Cecilia de Souza. Ciência, técnica e arte: o desafio da pesquisa social. In: MINAYO, Maria Cecilia Souza (org.). Pesquisa social: teoria, método e criatividade. Petrópolis: Editora Vozes, 2010. p. 09-29

NEVES, Eduardo Góes. Os índios antes de Cabral: arqueologia e história indígena no Brasil. In: A TEMÁTICA INDÍGENA NA ESCOLA. Brasília: MEC/UNESCO, 1995.

SYMANSKI, Luis Claudio. As teorias da arqueologia e suas relações e contrastes com a história. Revista Histórica, Porto Alegre, v. 1, n.2, p. 26-33, 1997.

ROMANELLI, Otaíza de Oliveira. História da educação no Brasil (1930/1973). 8. Ed. Petrópolis: Vozes, 1986.

SOUZA, Alfredo Mendonça de. Dicionário de arqueologia. Rio de Janeiro: ADESA, 1990.

TRIGGER, Bruce Graham. Além da história: os métodos da pré-história. São Paulo: Universidade de São Paulo, 1973. p. 01-08.

TRIGGER, Bruce Graham. História do pensamento arqueológico. São Paulo: Odysseus, 2004.

VICENTINO, Cláudio. Projeto mosaico: história. 3.ed. São Paulo: Scipione, 2016.

\section{Coleções utilizadas}

APOLINÁRIO, Maria Raquel. Projeto Araribá: história. 4.ed. São Paulo: Moderna. 2014.

BOULOS JUNIOR, Alfredo. História, sociedade \& cidadania. 3.ed. São Paulo: FTD, 2015.

COTRIM, Gilberto. Historiar. 2.ed. São Paulo: Saraiva, 2015.

PELLEGRINE, Marco César. Vontade de saber história. São Paulo: FTD, 2015.

VICENTINO, Cláudio. Projeto mosaico: história. 3.ed. São Paulo: Scipione, 2016. 
Recebido em: 04/05/2020 Aprovado em: 14/01/2021

Universidade do Estado de Santa Catarina - UDESC Centro de Ciências Humanas e da Educação - FAED PerCursos

Volume 21 - Número 47 - Ano 2020 revistapercursos@gmail.com 